\title{
Preventive healthcare uptake in private hospitals in Nigeria: a cross-sectional survey (Nisa premier hospital)
}

\author{
Joshua N. T. Ofoli' ${ }^{1}$, Timi Ashau-Oladipo', Stephen S. Hati ${ }^{2,3}$, Lile Ati ${ }^{2}$ and Victor Ede ${ }^{4^{*}}$
}

\begin{abstract}
Background: Understanding the features of preventive care uptake is critical for assessing the performance and viability of primary care in any healthcare system. There are gaps in previous studies that focused on primary healthcare features, challenges and way forward in Nigeria but were mainly public sector focused and do not characterize the features of preventive care. Since private healthcare sector remains the most accessed and utilized in Nigeria, this study sought to characterize the features of uptake of preventive care to better understand the current preventive healthcare landscape.

Method: A descriptive cross-sectional study, using survey questionnaire were randomly administered to adult patients attending the Family Medicine Out-Patient Department (OPD) at Nisa Premier Hospital, Jabi Abuja. The study was conducted over a three-month period. (January to June 2017). Data collected were analyzed using SPSS version 23 (IBM SPSS, Chicago, IL, USA). Descriptive statistics in the form of frequency and percentage were used to report the results.
\end{abstract}

Results: A total of 381 participants completed the survey. The results revealed that while an over overwhelming majority (>90\%) of participants indicated knowledge of benefits of preventive care, and preferred interventions aimed at preventing a disease before they occur, $48 \%$ preferred interventions aimed at reducing disease or injury impact or interventions aimed at ameliorating the impact of ongoing disease or injury with long lasting effect (43\%). Unfortunately, less than $40 \%$ of respondents would visit the hospital when their health condition is not serious. Important barriers to uptake of preventive care were revealed as cost (45\%), distance to the healthcare provider (36\%) and lack of health insurance (33\%), whereas poor education (19\%), social norms (13\%) as well as cultural and religious beliefs (10\%) towards accessing certain health services appeared to be lesser barriers.

Conclusion: Although people are aware of the benefits of preventive care, its uptake will greatly be enhanced through improved health insurance coverage, refocusing primary healthcare functions on preventive rather than curative care and instituting policies that mandatorily prescribe uptake for the insured, both at the individual and the insurer's level.

Keywords: Preventive healthcare, Characterization, Nisa hospital, Abuja, Private hospital, Primary healthcare, Health insurance cover

* Correspondence: edevictor@gmail.com
${ }^{4}$ Medical Audit Department, Nisa Premier Hospital, Abuja, Nigeria
Full list of author information is available at the end of the article

(c) The Author(s). 2020 Open Access This article is licensed under a Creative Commons Attribution 4.0 International License, which permits use, sharing, adaptation, distribution and reproduction in any medium or format, as long as you give appropriate credit to the original author(s) and the source, provide a link to the Creative Commons licence, and indicate if changes were made. The images or other third party material in this article are included in the article's Creative Commons licence, unless indicated otherwise in a credit line to the material. If material is not included in the article's Creative Commons licence and your intended use is not permitted by statutory regulation or exceeds the permitted use, you will need to obtain permission directly from the copyright holder. To view a copy of this licence, visit http://creativecommons.org/licenses/by/4.0/ The Creative Commons Public Domain Dedication waiver (http://creativecommons.org/publicdomain/zero/1.0/) applies to the data made available in this article, unless otherwise stated in a credit line to the data. 


\section{Background}

Disease and disability are dynamic processes which begin before individuals realize they are affected; therefore prevention of diseases largely relies on anticipatory actions which are termed preventive care [1]. It consists of measures taken for disease prevention, as opposed to disease treatment [1]. Preventive care services encompass a wide range of healthcare measures including routine check-ups, disease screenings, and immunizations, which can be undertaken to prevent the occurrence of disease and detect disease early [2,3].

Prior studies have shown that preventive care service utilization reduces premature mortality and improves quality of life $[2,4]$. Underutilization of preventive care services may result in failures to identify treatable healthcare problems and prevent potentially lifethreatening diseases [4]. According to estimates made by the World Health Organization (WHO), about 55 million people died worldwide in 2011, with two thirds of this group dying from non-communicable diseases and $60 \%$ of these deaths were attributed to preventable disease. Preventive healthcare is especially important, given the worldwide increase in the burden of chronic diseases and preventable deaths.

However, despite the clamor and advocacy for prevention, uptake of preventive health services is still poor $[5,6]$ owing to different factors such as age, income, insurance coverage, awareness, access to preventive services [7]. Many countries have adapted preventive care models, or are promoting preventive health services on the premise that prevention does not only improve health, but also has a cost-saving potential or confers substantial health benefits relative to their cost [8]. Researchers have argued about the effectiveness of applying a preventive measure towards the general population rather than direct prevention towards a target population [9]. Others refute this claim, stating that a particular preventive measure termed to give good value or poor value depends on factors such as the population targeted, with measures targeting higher-risk populations typically being the most efficient [8].

In addition, studies have shown that the factors that determine utilization apply differently to different settings; this was proven by exploring the inequality in utilization of preventive care services using different variables. For example, Chen et al. [9] and Ayanda [10] noted that rural residents were less likely to utilize preventive care services when compared to urban residents in China and Nigeria respectively. Conversely, Howe et al. identified existing age, race, income, and insurance status-related disparities in preventive care utilization within a US population [11]. One study also explored the private and public health sectors in health care delivery by comparing the services rendered in both sectors including preventive care [12]. The study reported that in Colombo, Sri Lanka, the private sector provided more than $72 \%$ of all childhood immunizations, among a population. Similarly, the Nigerian health system is a blend of both private and public health care with relatively more people seeking care in private settings for most of their health demands due to various reasons such as travel time, education, age, sex, level of education of household head, household size and perceived quality of care provided in the facility [13]. Considering these various factors, it will be important to explore utilization of the preventive health services provided in private hospital settings as this determines the success of any health delivery system. Therefore, in this study we sought to characterize the uptake of preventive healthcare and determine the rate of preventive care utilization in private hospitals in Nigeria. A number of studies have considered primary healthcare challenges and way forward in Nigeria [14, 15], but are mainly public sector focused and do not characterize the preventive health care landscape which is critical to primary healthcare. Since private health sector is the most accessed and utilized in Nigeria, characterizing the uptake of preventive health care will provide understanding of the available infrastructure, utilization, and barriers to preventive healthcare access.

\section{Methods \\ Study design}

This cross-sectional survey research was conducted from June 2017 to February 2018. Paper questionnaires were administered by medical receptionists, patient care assistants and quality assurance officers in the family medicine Out-Patient Department (OPD). They were trained on the process of questionnaire administration for a period of 1 week. A representative convenience sample of patients, doctors, nurses, and support staff from the OPD were recruited into the study. The OPD offers emergency care services, outpatient visits, immunization, preventive care services, laboratory, radiological and drug refill services. The preventive healthcare services available in the hospital include pre-employment, preschool, women-centered, child wellness, and diabetic packages.

\section{Survey frame}

According to Wada et al. (2016), the case study, Nisa Premier Hospital, has in its database over 50,000 registered patients as at 2014 [15]. In adopting the sample frame, the monthly average number of visits to the Family Medicine OPD which constitutes $70 \%$ of visits per month in a polyclinic setting was utilized. 
The sample size was calculated with a confident level of $95 \%$ and a confidence interval of $5 \%$ a sample size of 346 respondents from a total sample frame of 3500 . The confidence interval of $5 \%$ suggests that between 45 and $55 \%$ of the study population would provide the answers that were obtained from this study. The attrition rate was set at $10 \%$ of sample size (35), which gave a total sample size of 381. Questionnaires were administered to a total of 586 adults. There was a $65 \%$ response rate; hence 381 completed questionnaires were used for analysis. Informed consent forms were reviewed and approved by the Nisa Scientific Review Committee. Written informed consent to participate in the study was obtained from all participants prior to participation.

\section{Inclusion criteria}

The inclusion criteria included participants between ages 18 years to 65 years, visiting the OPD as patients or staff of the hospital. Both males and females who were literate and medically stable were invited to participate.

\section{Exclusion criteria}

Children below the age of 18 and older adults above 65 years, in-patients and the very ill patients of other sub specialties were excluded along with patients who could not give consent.

\section{Survey instrument}

Due to a paucity of questionnaires on this subject in the region of interest, the researchers developed their own questionnaire using relevant books, studies and references and in accordance with the Theory of Planned Behavior (TPB). The questionnaire included multiple choice questions relating to factors that affect preventive health care uptake (see Supplementary file 1). The questionnaire asked the participants' demographic information, including age group, gender, level of education, marital status, employment, monthly income, distance from nearest health clinic/hospital, and examined the constructs of TPB; including attitude, subjective norms, perceived behavioral control, behavioral intention and behavior. Cronbach's alpha values were calculated to confirm the reliability of each of the constructs.

Behavioral intention (nine items), attitude (two items), subjective norms (two items) and perceived behavioral control (five items) were assessed based on a five-point Likert scale with responses ranging from 1 (never) to 5 (every 5 years); four-point scale ranging from 1 (life threating) to 4(not serious); and 'yes' (1 point) and 'no' (0 points) responses. Ultimately, behavior was assessed with 22 items, one of which was scored based on the Likert scale and the remaining 21 by 'yes' ( 1 point) and 'no' (0 points) responses.
The reliability of the items pertaining to the constructs of the TPB was confirmed by measuring their Cronbach's alpha, which was reported as $\alpha=0.74$ for attitude, $\alpha=0.74$ for subjective norms, $\alpha=0.74$ for perceived behavioral control, $\alpha=0.74$ for behavior and $\alpha=0.74$ overall. The questionnaire took $15 \mathrm{~min}$ to be completed.

Questions asked to determine health seeking behavior of respondents include "Where do you usually go if you are sick or to treat a general health problem?" which had the following options private hospitals, general hospitals, drug store and natural healers, "How often do you seek health care at a clinic or Hospital?", whether monthly, half yearly, annually or every 2 years, and a question on the severity of an illness before seeking care where the options included life threatening, very serious, somewhat serious, and not serious.

We assessed adoption of preventive health measures using the following questions: (1) Are you aware of the term preventive health care? (2) Which aspect of preventive healthcare do you prefer? Options varied from: Interventions aimed at preventing a disease before they occur; Interventions aimed at reducing disease or injury impact; Interventions aimed at ameliorating the impact of on-going disease or injury with long lasting effect; All and none of the above. (3) Which of the following constitute preventive health care? The option include Preventive health check-ups/physical exams, Regular age related screening tests, Lifestyle- related advice like diet/ nutritional counseling, Facilities for exercising like gym or park, Stress-relieving techniques like Yoga, and Routine vaccinations (4) How often or at what interval do you undergo preventive health check-up? (5) What preventive health measure do you take? Amongst Immunization, Insecticide Treated Nets, Exercise, Dieting, Stress management, Weight control, Yoga and Prophylaxis? (6) Which preventive healthcare services have you accessed in the past 2 years? (7) Which of these would prevent you from accessing preventive health care? With options including Poor access/distance to the healthcare providers, Cultural and religious beliefs, Underutilization of available health information, Inadequate/lack of Health insurance coverage, Stigma and social norms towards accessing certain health services, Inadequate education on benefits of Preventive Healthcare and Cost of healthcare (see Supplementary file 1). Questions 1 and 3 assessed knowledge of preventive healthcare while questions 4, 6 and 7 were used to assess the uptake of preventive healthcare services. Responses to knowledge and uptake of preventive healthcare constructs were categorized and coded into yes or no. The survey instrument was piloted among 20 staff at a large partner hospital in Abuja for a period of 1 week. The staff's feedbacks were compared for consistency and redundancy. Additional domains of interest were also 
identified. The survey was further evaluated for relevancy, clarity and appropriateness of responses by four more staff. Modifications were made to the survey in response to this review.

Paper data were collected and entered on an excel sheet. Analysis was done using SPSS statistical package version 23 (IBM SPSS, Chicago, IL, USA). Descriptive statistics in the form of frequency and percentage were used to report the results. Differences in responses by participant demographic characteristics were determined using the 2 - sided Chi-square test.

\section{Results}

A total of 381 participants completed the survey. The participant's ages ranged from 18 to 65 years with the majority $(80.0 \%)$ between the ages of 25 and 44 years (Table 1). In terms of gender, $61.0 \%$ of the subjects were female. The majority (98\%) of the participants had attained either tertiary or postgraduate education. About $78.0 \%$ of the participants were married mothers and more than half $(55 \%)$ of the participants estimated their monthly income at 100,001-400,000 naira. As shown in Table 1 , over $70 \%$ of the participants lived within $10 \mathrm{~km}$ from a clinic or hospital. Seventy-seven percent of participants indicated that they usually seek health care in a private hospital. Table 2 states that only $13 \%$ of participants go to public hospital when they are sick. Regarding factors that determine choice of hospital, the majority of participants $(74 \%)$ chose a hospital based on the availability of specialized doctors and qualified health staff. Almost half of the participants indicated that the ease of accessing care, wait time to receive care $(45 \%)$, staff courtesy/friendliness (42\%) and the cleanliness of the hospital (43\%) all influence their choice of hospital (See Table 2).

In assessing the seriousness of an ailment prompting visit to a health facility, about half (51\%) of the participants would wait until their condition was somewhat serious. However, 39\% of participants mentioned that they would visit the hospital when their health condition is not serious (Table 2). With regard to awareness of the term preventive health care, $87 \%$ of the participants knew what preventive health was. Table 3 depicts that the overwhelming majority (91\%) of participants preferred interventions aimed at preventing a disease before they occur whereas near half preferred interventions aimed at reducing disease or injury impact $(48 \%)$ or interventions aimed at ameliorating the impact of ongoing disease or injury with long lasting effect (43\%). When asked what preventive health measures they take, $61 \%$ mentioned exercise, followed by immunization (48\%), and dieting (41\%). Over the past 2 years, blood pressure (65\%), blood sugar (54\%)
Table 1 Demographic characteristics

\begin{tabular}{|c|c|}
\hline Characteristics & N (\%) \\
\hline \multicolumn{2}{|l|}{ Age (Years) } \\
\hline $18-24$ & $29(8)$ \\
\hline $25-34$ & $176(46)$ \\
\hline $35-44$ & $131(34)$ \\
\hline $45-54$ & $36(9)$ \\
\hline $55-65$ & $9(2)$ \\
\hline \multicolumn{2}{|l|}{ Gender } \\
\hline Female & $231(61)$ \\
\hline Male & $150(39)$ \\
\hline \multicolumn{2}{|l|}{ Highest level of education } \\
\hline Postgraduate & $214(56)$ \\
\hline Primary & $1(0)$ \\
\hline Secondary & $5(1)$ \\
\hline Tertiary & $161(42)$ \\
\hline \multicolumn{2}{|l|}{ Marital Status } \\
\hline Married & $297(78)$ \\
\hline Separated & $3(1)$ \\
\hline Single & $81(21)$ \\
\hline \multicolumn{2}{|l|}{ Type of Employment } \\
\hline Unemployed & $11(3)$ \\
\hline Government & $114(30)$ \\
\hline Non-Governmental Organization & $1(0)$ \\
\hline Private & $183(48)$ \\
\hline Self-employed & $72(19)$ \\
\hline \multicolumn{2}{|l|}{ Monthly Income（） } \\
\hline$<100,000$ & $117(31)$ \\
\hline $100,001-400,000$ & $209(55)$ \\
\hline $400,001-1,000,000$ & $39(10)$ \\
\hline$>1,000,000$ & $16(4)$ \\
\hline \multicolumn{2}{|l|}{ Distance from nearest hospital } \\
\hline$>15 \mathrm{~km}$ & $50(13)$ \\
\hline$\leq 5 \mathrm{~km}$ & $166(44)$ \\
\hline $11-15 \mathrm{~km}$ & $39(10)$ \\
\hline $6-10 \mathrm{~km}$ & $126(33)$ \\
\hline
\end{tabular}

Note: $k m$ Kilometer; Naira

and weight (49\%) checks were the top 3 preventive health care services accessed by participants. Access or utilization of age-specific and gender-specific preventive healthcare services such as pap smear (15\%), colon cancer screen (1\%), prostate cancer screen (4\%), chlamydia screening (3\%) and mammography (5\%) were low likely due to our participant demographic (see Table 4).

As for barriers to access to preventive healthcare shown in Tables 4, 45\% of the participants indicated that the cost 
Table 2 Health seeking behavior

\begin{tabular}{|c|c|}
\hline Variables & N (\%) \\
\hline \multicolumn{2}{|c|}{ Place of choice to go to for illness/treatment } \\
\hline Drug store (Pharmacy) & $37(10)$ \\
\hline Government hospital & $50(13)$ \\
\hline Private Clinic & $293(77)$ \\
\hline Others & $1(0)$ \\
\hline Traditional healer & $0(0)$ \\
\hline \multicolumn{2}{|l|}{ Frequency of hospital visits } \\
\hline Every 6 months & $147(39)$ \\
\hline Every 1 year & $68(18)$ \\
\hline Monthly & $113(30)$ \\
\hline Two years above & $37(10)$ \\
\hline When there is need & $16(4)$ \\
\hline \multicolumn{2}{|c|}{ Factors that determine choice of hospital } \\
\hline OProximity & $111(29)$ \\
\hline Working hours of health facility & $67(18)$ \\
\hline Staff courtesy & $159(42)$ \\
\hline Qualified health staff & $281(74)$ \\
\hline Waiting time & $171(45)$ \\
\hline Cleanliness of facility & $162(43)$ \\
\hline Reputation of health facility & $144(38)$ \\
\hline Cost of services & $83(22)$ \\
\hline \multicolumn{2}{|c|}{ Extent of illness before visiting healthcare facility } \\
\hline Life threatening & $10(3)$ \\
\hline Not serious & $150(39)$ \\
\hline Somewhat serious & $193(51)$ \\
\hline Very serious & $28(7)$ \\
\hline \multicolumn{2}{|c|}{$\begin{array}{l}\text { Diseases that have required hospital intervention in the past } 1 \\
\text { year }\end{array}$} \\
\hline Acute diseases & $263(69)$ \\
\hline Infectious diseases & $18(5)$ \\
\hline Chronic diseases & $49(13)$ \\
\hline None of the above & $32(18)$ \\
\hline Others & 34 (9) \\
\hline
\end{tabular}

of healthcare prevented them from accessing preventive health care. Among study participants, high healthcare cost was the most frequent barrier to preventive care access followed by distance to the healthcare provider (36\%) and lack of health insurance (33\%). Whereas cultural and religious beliefs (10\%), stigma and social norms towards accessing certain health services (13\%), and inadequate education on the benefits of preventive healthcare were lesser barriers to accessing preventive health care (19\%). Of the preventive healthcare packages offered, the majority $(67 \%)$ of participants indicated that they would access the 'routine complete checkup package'.
We observed significant differences in demographics relative to knowledge and uptake of preventive healthcare. Table 5 show that females $(57.8 \%)$ were more likely to have knowledge of the components of preventive healthcare compared to males $(p<0.001)$. Individuals who were married frequently accessed preventive health care than those who were single or unmarried. The age ranges 25-34 years and 35-44 years were more likely to frequently access preventive health care and had in the past 2 years accessed a preventive healthcare service than were other age groups. Compared with other forms of employment, privately employed individuals (50.6\%) were more likely to have knowledge about the preventive health care services available to them.

\section{Discussion}

In this study nearly half of the participants were employed by private entities and had high literacy levels which may not be reflective of the employment type and literacy rates of the broader population. However, the distribution of age, gender, and marital status variable is comparable to that seen in the general population. We also found that the majority of participants lived less than $10 \mathrm{~km}$ from the nearest health care facility where they seek care and these points of care were mostly private clinics.

Monthly income was mostly between 100,000 to 400 , 000 naira (279 to 1116 USD). Based on world bank poverty and equity data portal for Nigeria, all participants were above the upper middle-income class poverty line [16]. Thus, in contrast with the general population, the average income level of our study participants was not representative of the income of most (53.5\%) Nigerians who earn 20,520 naira (57 USD) monthly. Our study did not assess the statistical correlation between participant's income level and the uptake of preventive health service.

From this study, as with public health studies of most Sub-Saharan countries [17], there is a lack of universal health coverage with a limited range of services and benefits covered. Furthermore, as a growing number of low and middle-income countries commit to achieving universal health coverage, one key challenge is how to extend coverage to the private sector [18]. The majority of Sub-Saharan African population access health care in private healthcare facilities [19]. Similarly, our study revealed that the majority of participants sought primary care in private healthcare settings and paid out-of-pocket for their health care. This is because less than $10 \%$ of the total Nigerian population is covered by the National Health Insurance Scheme (NHIS) [20, 21]. The NHIS is the government agency charged with securing universal coverage and access to adequate and affordable healthcare in order to improve the health status of 
Table 3 Awareness of preventive health care

\begin{tabular}{lc}
\hline Variables & $N(\%)$ \\
\hline Awareness & $51(13)$ \\
No & $330(87)$ \\
Yes & 113 (30) \\
Source of awareness & $114(30)$ \\
Mass media & $141(37)$ \\
Social media & $99(26)$ \\
Health workers & $20(5)$ \\
Family friends & $44(12)$ \\
Religious/Community leaders & \\
Others &
\end{tabular}

\section{Preferred aspect of Preventive healthcare}

Intervention aimed at preventing a disease before they occur

Interventions aimed at reducing disease or injury impact

Interventions aimed at ameliorating the impact of ongoing disease or injury with long lasting effect

\section{Preventive health care components}

Preventive health check-ups/physical exams

Regular age related screening tests

Lifestyle-related advice like diet/nutritional counseling

Facilities for exercising like gym or park

Stress-relieving techniques like Yoga

$201(53)$

Routine vaccinations

Others

Preventive health checkup interval

6 monthly

Annually

Every 5 years

Every 2 years

Never

\section{Participant preventive health care measures}

Immunization

Exercise

Dieting

Stress management

Yoga

Nigerians [20]. For the covered 10\%, incorporating preventive health care packages to the NHIS plans may go a long way in improving the uptake of preventive health care. This is on the basis of the $\mathrm{Na}$ tional Health Act (NHA) that mandates a basic minimum health care package and provides funding for this package [22]. Even more imperative is the need to expand the NHIS coverage to include all eligible Nigerians who are currently not covered.

An important finding of our study is that the cost of health care is a significant barrier to the access of preventive health care. This is despite the relatively higher income levels of the study population when compared with the general population. We can therefore project 
Table 4 Uptake of preventive health care services

\begin{tabular}{|c|c|}
\hline Variables & N (\%) \\
\hline \multicolumn{2}{|l|}{ Preventive health care services accessed in past 2 years } \\
\hline Pap smear & $57(15)$ \\
\hline BP check & $249(65)$ \\
\hline Blood sugar & $207(54)$ \\
\hline Cholesterol/lipids & $90(24)$ \\
\hline Screening for STIs (Including HIV) & $162(43)$ \\
\hline Screening for Hepatitis B \& C & $147(39)$ \\
\hline Chlamydia screen & $10(3)$ \\
\hline Colon cancer screen & $4(1)$ \\
\hline Prostate cancer screen & $17(4)$ \\
\hline Dental screen & $85(22)$ \\
\hline Eye care & $124(33)$ \\
\hline Weight check & $188(49)$ \\
\hline Others (specify) & $5(1)$ \\
\hline \multicolumn{2}{|l|}{ Barriers to preventive health care access } \\
\hline Poor access/distance to the health care providers & $137(36)$ \\
\hline Cultural and religious beliefs & $40(10)$ \\
\hline Underutilization of available health information & $66(17)$ \\
\hline Inadequate/lack of health insurance coverage & $127(33)$ \\
\hline Stigma and social norms towards accessing certain health services & $49(13)$ \\
\hline Inadequate education on benefits of preventive healthcare & $74(19)$ \\
\hline Cost of health care & $173(45)$ \\
\hline None of the above & $34(9)$ \\
\hline Others (please specify) & $4(1)$ \\
\hline \multicolumn{2}{|l|}{ Preferred preventive health care packages } \\
\hline Domestic staff screening & $99(26)$ \\
\hline Pre-employment test & $91(24)$ \\
\hline Preschool screening test & $72(19)$ \\
\hline Advanced heart check & $78(20)$ \\
\hline Diabetic package & $73(19)$ \\
\hline Liver screening package & $75(20)$ \\
\hline Pre-marital screening & $98(26)$ \\
\hline Routine complete check-up & $254(67)$ \\
\hline Senior citizens check-up & $36(9)$ \\
\hline
\end{tabular}

that the impact of the high cost of healthcare may be higher in the general population. Addressing this cost barrier by ensuring that a third-party payer such as NHIS covers the cost of preventive health care may improve access. Eliminating the cost barrier will in the long term be cost effective for the Nigerian health system as it would have greater population benefit. Challenges stemming from NHIS-delayed reimbursements, cost recovery and low revenue for primary health care services are faced by private health providers [19]. Hence forprofit private health sector providers may be averse to offering comprehensive preventive care programs due to these problems. Having a population-wide intervention through the NHIS that expands coverage and offers incentives to the primary care providers to offer preventive healthcare as well as offset the cost to the facility would possibly improve motivation to participate in the scheme and make care more accessible [19]. In addition, since most participants in the study were employed in private settings, more should be demanded from the selfemployed and other private employers to provide health care coverage or insurance for their employees through 
Table 5 Cross-tabulation of demographic characteristics and preventive healthcare services uptake

\begin{tabular}{|c|c|c|c|c|c|c|c|c|c|c|}
\hline & \multicolumn{4}{|c|}{ Knowledge of Preventive Healthcare } & \multicolumn{6}{|c|}{ Utilization of Preventive Healthcare Services } \\
\hline & \multicolumn{2}{|c|}{$\begin{array}{l}\text { Awareness of } \\
\text { Preventive } \\
\text { Healthcare }\end{array}$} & \multicolumn{2}{|c|}{$\begin{array}{l}\text { Knowledge of the } \\
\text { components of } \\
\text { Preventive Healthcare }\end{array}$} & \multicolumn{2}{|c|}{$\begin{array}{l}\text { Frequency of } \\
\text { Preventive Healthcare } \\
\text { Visits }\end{array}$} & \multicolumn{2}{|c|}{$\begin{array}{l}\text { Two-Year Uptake of } \\
\text { Preventive Healthcare } \\
\text { Services }\end{array}$} & \multicolumn{2}{|c|}{$\begin{array}{l}\text { Future Planned Access to } \\
\text { Preventive Healthcare } \\
\text { Services }\end{array}$} \\
\hline & N (\%) & $p$ & N (\%) & $p$ & $N(\%)$ & $p$ & N (\%) & $p$ & N (\%) & $p$ \\
\hline Age & & 0.217 & & 0.012 & & 0.012 & & 0.014 & & 0.259 \\
\hline $18-24$ & $22(6.7)$ & & $23(6.6)$ & & $16(5.6)$ & & $21(6.2)$ & & $24(7.1)$ & \\
\hline $25-34$ & $159(48.2)$ & & $154(44.5)$ & & $129(45.4)$ & & $155(45.6)$ & & $152(44.8)$ & \\
\hline $35-44$ & $111(33.6)$ & & $125(36.1)$ & & $98(34.5)$ & & $121(35.6)$ & & $121(35.7)$ & \\
\hline $45-54$ & $30(9.1)$ & & $35(10.1)$ & & $32(11.3)$ & & $35(10.3)$ & & $33(9.7)$ & \\
\hline $55-65$ & $8(2.4)$ & & $9(2.6)$ & & $9(3.2)$ & & $8(2.4)$ & & $9(2.7)$ & \\
\hline Gender & & 0.981 & & 0.000 & & 0.06 & & 0.771 & & 0.858 \\
\hline Female & $200(60.6)$ & & $200(57.8)$ & & $180(63.4)$ & & $207(60.9)$ & & $205(60.5)$ & \\
\hline Male & $130(39.4)$ & & $146(42.2)$ & & $104(36.6)$ & & $133(39.1)$ & & $134(39.5)$ & \\
\hline Education Level & & 0.079 & & 0.091 & & 0.108 & & 0.403 & & 0.134 \\
\hline Postgraduate & $187(56.7)$ & & $193(55.8)$ & & $167(58.8)$ & & $195(57.4)$ & & $188(55.5)$ & \\
\hline Primary & $0(0)$ & & $1(0.3)$ & & $1(0.4)$ & & $1(0.3)$ & & $1(0.3)$ & \\
\hline Secondary & $4(1.2)$ & & $3(0.9)$ & & $5(1.8)$ & & $5(1.5)$ & & $3(0.9)$ & \\
\hline Tertiary & $139(42.1)$ & & $149(43.1)$ & & $111(39.1)$ & & $139(40.9)$ & & $147(43.4)$ & \\
\hline Marital Status & & 0.615 & & 0.476 & & 0.018 & & 0.739 & & 0.413 \\
\hline Married & $255(77.3)$ & & $272(78.6)$ & & $230(81)$ & & $266(78.2)$ & & $266(78.5)$ & \\
\hline Separated & $3(0.9)$ & & $3(0.9)$ & & $3(1.1)$ & & $3(0.9)$ & & $2(0.6)$ & \\
\hline Single & $72(21.8)$ & & $71(20.5)$ & & $51(18)$ & & $71(20.9)$ & & $71(20.9)$ & \\
\hline Employment Status & & 0.009 & & 0.112 & & 0.443 & & 0.108 & & 0.242 \\
\hline Applicant & $7(2.1)$ & & $8(2.3)$ & & $8(2.8)$ & & $8(2.4)$ & & $9(2.7)$ & \\
\hline Government & $99(30)$ & & $105(30.3)$ & & $88(31)$ & & $100(29.4)$ & & $104(30.7)$ & \\
\hline Private & $168(50.9)$ & & $172(50.4)$ & & $130(45.8)$ & & $171(50.3)$ & & $167(50.2)$ & \\
\hline Self-employed & $56(17)$ & & 62 (17.9) & & $58(20.4)$ & & $61(17.9)$ & & 59 (17.4) & \\
\hline
\end{tabular}

private healthcare funders. As with the Affordable Care Act (ACA), adopting incentivized and/or subsidized preventive screening and health promotion programs - the structure of which increase the likelihood that beneficiaries will make positive lifestyle and healthy behavior choices, may help improve access to preventive health care $[23,24]$. The incentives may take the form of a lower premium for participation in preventive screening [25]. This may also include additional reimbursements to physicians to encourage implementation of preventive care guidelines.

Individuals who were privately employed appeared to be more aware of available preventive health care services. Furthermore, while majority of patients showed good knowledge of the term 'preventive health care', at least half of the patients yet mentioned that an illness should be somewhat serious before visiting a health facility. Focusing on interventions that enhances the translation of knowledge of preventive health to implementation behaviors might be important to improve uptake of preventive health. An innovative approach in our primary care facility would be develop an integrative model of care that offers preventive health care services to all patients who come to the OPD seeking care for other medical conditions. This is based on our findings that suggest that apparently healthy individuals normally seek care when somewhat or acutely sick. Age specific and risk factor modified preventive healthcare screen reminders may also improve physician implementation of integrated preventive care protocols.

\section{Conclusion}

Our results suggest that there may be relative lack of knowledge and poor preventive healthcare uptake rates among middle-aged and above individuals in Abuja who need to access preventive health care. Improving population education on the benefits of preventive healthcare and access to especially age-specific preventive health care services may help overall uptake of preventive healthcare. This study also revealed that despite 
awareness by some individuals, they still would not access preventive health care services until they fall sick. We have tried to explore factors that influence their uptake of these services and have recommended ways to improve this uptake. However, the survey constructs of our study did not allow us to correlate the statistical significance of these factors as well as how and why they impact on the uptake of preventive healthcare. Our next step would focus on identifying these associations and correlations. Furthermore, a limitation of our study was the lack of extension to other private healthcare facilities which may have been more revealing. However, this study is the first to our knowledge to characterize preventive health care uptake in private hospital settings in Nigeria and further research that includes a broader patient base is needed to validate these findings.

\section{Supplementary information}

Supplementary information accompanies this paper at https://doi.org/10. 1186/s12913-020-05117-5.

Additional file 1.

\section{Abbreviations}

OPD: Out-patient department; WHO: World health organization; TPB: Theory of planned behavior; NHIS: National health insurance scheme; NHA: National Health Act; ACA: Affordable care act

\section{Acknowledgements}

The authors would like to acknowledge the patients, staffs and management of Nisa Hospital Abuja for their participation and contribution to the success of this study. We also acknowledge Ms., Peace Opurum for assisting with data collection, data entry, and descriptive statistical analysis for this study.

\section{Consent to participate}

Not Applicable.

\section{Authors' contributions}

JNTO conceptualized and designed the study, contributed to the writing of the discussion section of the paper and approved the final article as submitted. VE interpreted the statistical analysis of the data, contributed to the writing of the results, discussion and conclusion sections of manuscript; he also reviewed, revised, approved, and submitted the final article. TAO wrote the introduction/Background section and defined the rationale of the study supervised, and approved the final article as submitted. LA contributed to writing the methods section of the paper and approved the final article as submitted. SSH wrote the abstract section of the manuscript, assisted with the design and piloting of the survey instrument, and approved the final article as submitted.

\section{Funding}

There were no sources of funding for this study.

\section{Availability of data and materials}

The datasets used and/or analyzed during the current study are available from the corresponding author on reasonable request.

\section{Ethics approval and consent to participate}

This cross-sectional survey research was approved by the Scientific Review Committee at Nisa Premier Hospital, Abuja, Nigeria. Written informed consent to participate in the study was obtained from all participants prior to participation.

\section{Competing interests}

The authors declare that they have no competing interests.

\section{Author details}

${ }^{1}$ Department of Family and Specialty Medicine, Nisa Premier Hospital, Abuja, Nigeria. ${ }^{2}$ Research and Development, Nisa Premier Hospital, Abuja, Nigeria.

${ }^{3}$ Center for Research, Institute of Medical Sciences Africa, Abuja, Nigeria.

${ }^{4}$ Medical Audit Department, Nisa Premier Hospital, Abuja, Nigeria.

Received: 15 August 2018 Accepted: 18 March 2020

Published online: 01 April 2020

\section{References}

1. Chiolero A, Paradis G, Paccaud F. The pseudo high-risk prevention strategy. Int J Epidemiol. 2015;44(5):1469-73.

2. Xiang L, Ningxiu L, Chaojie L, Xiaohui R, Danping L, Bo G, Yuanyuan L. Urban-rural disparity in utilization of preventive care services in China. Medicine. 2016;95(37):4783.

3. Vaidya V, Partha G, Howe J. Utilization of preventive care services and their effect on cardiovascular outcomes in the United States. Risk Manage Health Policy. 2011;4:1-7.

4. Odjidja EN, Kwanin C, Saha M. Low Uptake of Intermittent Preventive Treatment in Ghana; An Examination of Health System Bottlenecks. Health Res Policy Syst. 2017:4(3):58 1-5.

5. Labeit A, Peinemann F, Baker R. Utilisation of preventative health check-ups in the UK : findings from individual-level repeated cross-sectional data from 1992 to 2008. Br Med J. 2013;3(12):e003387.

6. Black LI, Nugent CN, Vahratian A. Access and Utilization of Selected Preventive Health Services Among Adolescents Aged 10-17. NCHS Data Brief. 2016;246:1-8.

7. Cohen JT, Neumann PJ, Weinstein MC. Does preventive care save money? Health economics and the presidential candidates. N Engl J Med. 2008; 358(7):661-3.

8. Mackenbach JP, Lingsma HF, Van Ravesteyn NT, Kamphuis CBM. The population and high-risk approaches to prevention: quantitative estimates of their contribution to population health in the Netherlands 1970-2010. Eur J Pub Health. 2012;23(6):909-15.

9. Chen $L, L u Y, C a o$ Q. The demand for preventive care services of residents in China and its influencing factors. Chinese Gen Pract. 2015;4:022.

10. Ayanda JO. Utilization of health care services in rural and urban areas : a determinant factor in planning and managing health care delivery systems. Afr Health Sci. 2014;14(2):322-33.

11. Howe J, Vaidya V, Partha G. Utilization of preventive care services and their effect on cardiovascular outcomes in the United States. Risk Manag Healthc Policy. 2011;4:1-7.

12. Basu S, Andrews J, Kishore S, Panjabi R, Stuckler D. Comparative performance of private and public healthcare Systems in low- and MiddleIncome Countries : a systematic review. PLoS Med. 2012;9(6):e1001244.

13. Uchendu OC, llesanmi OS, Olumide AE, Centre FM, State O. Factors influencing the choice of Health care providing facility among workers in a local government secretariat in South Western Nigeria. Ann Ibadan Postgrad Med. 2013;11(2):87-95.

14. Abiodun OA, Olu-Abiodun OO. The determinants of choice of Health Facility in Sagamu, south-west, Nigeria. Sch J Appl Med Sci. 2014;1(2):274-82.

15. Rabi W, Stephen H, Joshua O, Ibrahim W. Service quality domains impelling Patient's return intentions in Nisa premier hospital, Abuja. Int J Bus Manag. 2016;12(1):44-56.

16. Poverty \& Equity Data Portal. 2018, http://povertydata.worldbank.org/ poverty/country/NGA. Accessed 12th June 2018

17. Paul E, Fecher F, Meloni R, Lerberghe W. Universal Health coverage in francophone sub-Saharan Africa: assessment of Global Health Experts' confidence in policy options. Glob Health. 2018;6(2):260-71.

18. Peterson L, Alison C, Laurel H, Thierryvan B. Extending health insurance coverage to the informal sector: lessons from a private micro health insurance scheme in Lagos, Nigeria. Int J Health Plann Manag. 2018;33(3): 662-76

19. Sieverding $M$, Onyango $C$, Suchman L. Private healthcare provider experiences with social health insurance schemes: findings from a qualitative study in Ghana and Kenya. PLoS One. 2018;13(2):e0192973.

20. National Health Insurance Scheme (NHIS). 1999, https://www.nhis.gov.ng/ About\%20us/. Accessed 15th June 2018. 
21. Kruk ME. Universal health coverage: a policy whose time has come. BMJ. 2013;347:f6360.

22. National Assembly. National Health Act, 2014: Explanatory Memorandum. 2014, https://nass.gov.ng/document/download/7990. Accessed 16 June 2018.

23. Lambert EV, Kolbe-Alexander TL. Innovative strategies targeting obesity and non-communicable diseases in South Africa: what can we learn from the private healthcare sector? Obes Rev. 2013;14(S2):141-9.

24. Blumenthal-Barby JS, Burroughs H. Seeking better Health care outcomes: the ethics of using the "nudge". Am J Bioeth. 2012;12(2):1-10.

25. Giuffrida A, Torgerson DJ. Should we pay the patient? Review of financial incentives to enhance patient compliance. BMJ. 1997;315(7110):703-7.

\section{Publisher's Note}

Springer Nature remains neutral with regard to jurisdictional claims in published maps and institutional affiliations.

Ready to submit your research? Choose BMC and benefit from:

- fast, convenient online submission

- thorough peer review by experienced researchers in your field

- rapid publication on acceptance

- support for research data, including large and complex data types

- gold Open Access which fosters wider collaboration and increased citations

- maximum visibility for your research: over $100 \mathrm{M}$ website views per year

At $\mathrm{BMC}$, research is always in progress.

Learn more biomedcentral.com/submissions 